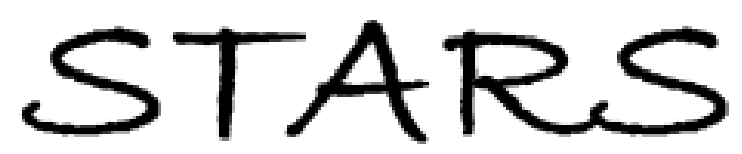

University of Central Florida

STARS

$11-1-2009$

\title{
A World Ranking of the Top 100 Hospitality and Tourism Programs
}

\author{
Denver E. Severt \\ University of Central Florida, denver.severt@ucf.edu \\ Dana V. Tesone \\ University of Central Florida, dana.tesone@ucf.edu \\ Tim Bottorff \\ University of Central Florida, timothy.bottorff@ucf.edu \\ Monica L. Carpenter
}

Part of the Hospitality Administration and Management Commons, and the Tourism and Travel Commons

Find similar works at: https://stars.library.ucf.edu/rosenscholar

University of Central Florida Libraries http://library.ucf.edu

This Paper is brought to you for free and open access by the Rosen College of Hospitality Management at STARS. It has been accepted for inclusion in Rosen Faculty Scholarship and Creative Works by an authorized administrator of STARS. For more information, please contact STARS@ucf.edu.

\section{Original Citation}

Severt, D., Tesone, D., Bottorff, T., \& Carpenter, M. (2009). A world ranking of the top 100 hospitality and tourism programs. Journal of Hospitality and Tourism Research, 33(4), 451-470.

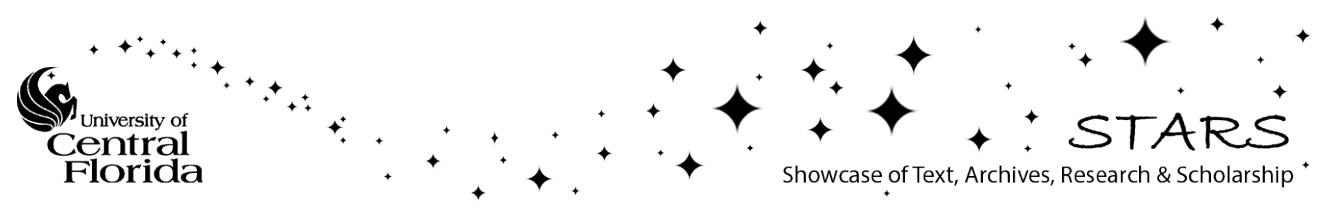




\author{
Dana V. Tesone \\ Associate Professor \\ University of Central Florida \\ 9907 Universal Boulevard \\ Orlando, Florida 32819 \\ Phone: (407) 903-8000 \\ Fax: (407) 903-8105 \\ dtesone@mail.ucf.edu \\ Denver E. Severt* \\ Associate Professor \\ University of Central Florida \\ 9907 Universal Boulevard \\ Orlando, Florida 32819 \\ Phone: (407) 903-8036 \\ Fax: (407) 903-8105 \\ dsevert@mail.ucf.edu \\ Timothy J. Bottorff \\ Assistant Librarian \\ University of Central Florida \\ 9907 Universal Boulevard \\ Orlando, Florida 32819 \\ Phone: (407) 903-8000 \\ Fax: (407) 903-8105 \\ tbottorf@mail.ucf.edu \\ Monica L. Carpenter, MS \\ Doctoral Student \\ University of Central Florida \\ 9907 Universal Boulevard \\ Orlando, Florida 32819 \\ Phone: (407) 903-8000 \\ Fax: (407) 903-8105 \\ mlcarpen@mail.ucf.edu \\ * Principal Contact
}

Submitted: May 2008 - Revision \# 3 to

Journal of Hospitality and Tourism Research 


\title{
A WORLD RANKING OF THE TOP 100 HOSPITALITY AND TOURISM PROGRAMS
}

\begin{abstract}
The article provides an analysis of scholarly contributions to 11 hospitality and tourism refereed journals for the years 2002-2006. It presents the top 100 programs as ranked by instances of publications across 11 journals for a recent five-year period. For the five-year period, results indicate Hong Kong Polytechnic University in the top position based on sums of instances, authors and articles. Secondly, the researchers updated, modified and extended a previous study published by the Journal of Hospitality and Tourism Research for similar information for the years 1992-2001. Following the update, an additional 15-year aggregate snapshot of research output for top producing institutions provided a top 18 over the last 15year period. Next, researchers provide an updated analysis by contribution and world region among the specific journals with results indicating a large growth in the number of articles produced in Asia going from 6\% of all publications over the former 10-year period from 1992 through 2001 to near 15\% of published articles over the past five-year period from 2002 through 2006. The article concludes with suggestions for the extension of similar studies and provides implications for hospitality and tourism educators.
\end{abstract}

Keywords: universities, hospitality journals, tourism journals, publications 


\section{A WORLD RANKING OF THE TOP 100 HOSPITALITY AND TOURISM PROGRAMS}

\section{INTRODUCTION}

The perceptual status of departments, programs, schools, and colleges within universities is based to some extent upon the ability of affiliated researchers to create and disseminate new knowledge (Trieschman, Dennis, Northcraft \& Niemi, 2000). Academic excellence is a term associated with many programs and departments of institutions that are recognized as possessing high quality research output (e.g., Neary, Mirrlees \& Tirole, 2003). By and large, institutional ranking for specific programs is typically determined by national and international research publication records (Arpan, Raney \& Zivnuska, 2003). Faculty members within these institutions often manage their research productivity independently with minimal guidance from institutional administrators (Bowen, 2005). The rankings based on research records and the independence associated with the research agenda is no exception for programs of hospitality and tourism management.

Pressure often accompanies a research stream. Embedded in this pressure are expectations that the researcher used sound methodologies, employed rigorous statistical testing, helped with the creation of theory and/or supported or refined current theories and finally, studied areas considered important to the respective research specialization of each faculty. Additionally, most tenure granting institutions set a goal for expectations regarding research output. Beginning tenure-track researchers might seek or be granted institutional support to assist in the development of a narrowly focused research stream. Tenured professors seem to independently evolve toward more pragmatic insights used to investigate and solve problems (Bolton \& Stolcis, 2003). For these reasons, pre-tenured professors commonly experience pressure to produce quality research streams as the means of attaining career security and 
progression (Cheng, Chan \& Chan, 2003). Thus the measurement of output across time by institutions and by various journals becomes an important activity for understanding contributions to knowledge as well as for various ranking reports that are produced for purposes of comparing programs and institutions.

Due to the importance of monitoring research progression, this article presents a five-year snapshot (2002-2006) of research contributions to 11 prominent hospitality and tourism journals. The snapshot is based on a blend of journals including hospitality journals, tourism journals and journals with an international focus. Based on this and because a previous study was being extended, the following journals were chosen for the analysis. The journals include The Annals of Tourism Research (Annals), The Cornell Hotel and Restaurant Administration Quarterly (CHRAQ), The Florida International University Hospitality Review (FIUHR), The International Journal of Contemporary Hospitality Management (IJCHM), The International Journal of Hospitality Management (IJHM), The Journal of Hospitality and Leisure Marketing (JHLM), The Journal of Hospitality and Tourism Education (JHTE), The Journal of Hospitality and Tourism Research (JHTR), The Journal of Travel Research (JTR), The Journal of Travel and Tourism Marketing (JTTM), and The Journal of Tourism Management (TM). The editors, affiliations and abbreviations for those journals are included in Table 1. The information presented represents the editors in place during the 2002 to 2006 time period analyzed in this article.

Table 1 about here 
The primary method used in the study involves aggregating research instances or a counting method to identify differences between institutions by contributions. The highlights are provided regarding output by institution in article instances, number of articles, number of contributing authors and world region. These are further classified according to a ranking of the top 100 hospitality and tourism management programs for 2002 to 2006, a world ranking of the top 20 programs classified by journal for 2002 to 2006, contributions by world regions classified by journal for 2002 to 2006, and a top 18 hospitality and tourism management programs for the years from 1992 to 2006. This and other reports concerning research contributions of any grouping of journals provide insights to current levels of scholarly activities within the hospitality and tourism disciplines. It also provides various frames of references (e.g., across time, by journal type and by region) allowing leadership to compare their research output with the output of other universities with similar and different types of weighting systems for teaching, research, and service activity. Finally, this research article focuses completely on research output in the journals mentioned.

First, the article presents the top 100 programs by instances also reporting total authors by institution. Secondly, the article serves as an update and an extension to a former JHTR study by Jogaratnam, McCleary, Mena, and Yoo (2005), which featured an examination of the contributions to the same journals by academic institutions during the period starting from the year 1992 through the year 2001. Aside from adding the top 100 universities and updating portions of the information since Jogaratnam et al. (2005), the researchers highlight significant changes in current five-year trends as compared with the former 10-year period previously reported. 


\section{LITERATURE REVIEW}

A number of content analyses with varying themes were published during the 1980s and 1990s. Dann, Nash and Pearce (1988) focused on articles in Annals of Tourism Research and the Journal of Leisure Research reviewing publications over the period of 1974 to 1986 . Chon, Evans and Sutherlin (1989) presented interesting findings concerning publications among four hospitality journals (CHRAQ, JHTR, IJHM, \& FIUHR). Reid and Andereck (1989) provided a content analysis of publications within three tourism journals (JTR, Annals, \& TM). A later study reviewed publications found within five leading hospitality journals (Crawford-Welch \& McCleary, 1992), which was later replicated by Baloglu and Assante (1999) showing that there was an increase in the use of multivariate statistics from earlier research. Other studies presented findings among either tourism or hospitality publications (Hing \& Dimmock, 1997). These studies though similar to this one were focused on a fewer number of selected journals.

The narrow scope of earlier studies may have been reflective of the limited number of existing hospitality and tourism journals during those years. There has certainly been a recent proliferation of additional academic journals in the field in more recent years. Some report the existence of between sixty and ninety possible journals related to tourism, hospitality, and business as publication avenues for hospitality and tourism research. Though the scope has broadened from previous studies, the authors acknowledge the multiple outlets for publication and refrain from making sweeping generalizations related to total publication records. This keeps the focus of this article and the subsequent rankings on only the 11 journals analyzed.

Some content analysis studies report findings that focus on a single publication, usually a commonly known premier journal such as Annals (e.g., Xiao \& Smith, 2006). The obvious limitation to single publication studies involves the exclusion of other tourism research outlets. 
Other studies presented analyses of research activities across a limited number of tourism journals (e.g., Annals, JTR, \& TM) during the eighties (Sheldon \& Collison, 1990; Sheldon, 1991). While the aforementioned studies provided findings representative of a broader range of publication outlets, the exclusive focus on tourism journals fails to account for productivity on the part of hospitality researchers.

Certain hospitality researchers conduct studies directly related to hotel, restaurant, airline, resort, spa, and casino operations (Sturman, 2005). For others, the primary focus concerns traditional business disciplines, such as finance, marketing, and human resource management. The latter group of researchers would be more likely to publish in both hospitality and nonhospitality refereed journals (Schmidgall \& Woods, 1993). It has been suggested that content analysis research should consider broader ranges of publication outlets to account for the varied venues of hospitality researchers (Roberts \& Shea, 2005). The readership of certain hospitality journals includes practitioners and academics (Newman, Scoffer \& Kay, 2001). It has been reported that a number of educators and students frequently review the hospitality literature to acquire information concerning lectures, student assignments, research information, and professional development (Schmidgall \& Woods, 1996). Research contributions to the content analysis literature appear to focus on quality and quantity related issues. Furthermore, many departments or programs are mixed between researchers espousing specialties in hospitality and tourism. This enhances the relevance for reviews including hospitality, tourism and journals with varied content including studies in hospitality and tourism.

Researchers have advocated citation analysis as a method to determine both quantity and quality of publications (Woods \& Schmidgall, 1995). The quantitative aspect appears in the number of times authors are cited in later contributions to the literature. Weaver and McCleary 
(1989) conducted a citation analysis of academic contributors from 1983 through 1987 across four journals. In 1990, Weaver, McCleary, and Farrar revisited this topic, extending the former analysis to include the period between the years 1983 and the year 1988. Additionally, Weaver, Wilson and McCleary (1990) examined the publication activity of the association members from the Academy of Marketing Science (AMS), the American Marketing Association (AMA) and Southern Marketing Association (SMA). This study was an extension of a previous study conducted by McCleary and Weaver (1987) providing a different viewpoint since many university faculty members are regularly involved in professional associations. Rutherford and Samenfink (1992) conducted a citation analysis from 1989 through 1999 reporting education’s most influential scholars among five major journals (CHRAQ, FIUHR, HRJ, JHRM, \& JHTE). Woods \& Schmidgall (2001) conducted an update and extension of the citation analysis by Weaver, McCleary, and Farrar (1990) covering the period of years from 1989 through the year 1999. In a later study, Rutherford and Samenfink (2002a) conducted a 10-year update to their citation analysis of the most influential scholars from hospitality and tourism education published within four journals (CHRAQ, FIUHR, IJHM, \& JHTR). However, these previous studies did not include tourism journals (e.g., Annals, TM, \& JTTM). A citation study combined hospitality and tourism journals and concluded that little cross citing existed between highly ranked hospitality (IJHM, CHRAQ, \& JHTR) and highly ranked tourism journals (Annals, JTR, \& TM). The article further concluded that more outside of both industry citing occurred than any other type of citing (Howey, Savage, Verbeeten, \& Van Hoof, 1999). The qualitative aspect is founded on the argument that suggests that higher quality works will be cited more frequently. In this sense, prominence is noted as those authors whose work is cited by other scholars in the production of new research. Also, journals with higher rankings tend to become more available 
within academic databases and are more commonly accessed in citation indices. Finally, studies conducting citation analysis still warn about the possible misinterpretations that can come from these studies adding to our argument for a variety of multi-method rankings and ratings to be performed (Jamal, Smith \& Watson, 2007).

During the 12th Annual Graduate Education and Graduate Student Research Conference in Hospitality and Tourism (2007) held in Houston, Texas, Dr. Kaye Chon, an editor of multiple journals (e.g., JHTR, JTTM) in the hospitality and tourism field, shared helpful tips for graduate students regarding the publication of work. Dr. Chon further discussed the evolvement of current journals and provided his opinion on the current top tier journals. According to Dr. Chon, the top-tier journals include IJHM, JHTR, TM, \& Annals. Hence, various ranking processes of journals have become the concern of contributors to the literature because journals that are more available in databases may be available to a broader range of readership. These are more likely to be found and more likely to be cited than journals that are not as accessible.

As suggested, there are many different beliefs regarding publications and scholarly activity. One study reported that 37 percent of Council of Hotel Restaurant Institutional Education (CHRIE) respondents (program directors) admitted to the hierarchical rankings of refereed journals within their institutions (Ferreira, DeFranco \& Rappole, 1994). It has been suggested that ranking studies could differentiate classification according to pure research journals and applied management journals (Roberts \& Shea, 2005). Others contended that journals should be rated on readership frequency, scientific and practical relevance, and overall reputation among academics (Pechlaner, Zehrer, Matzler \& Abfater, 2004). Another assertion prescribed rigorous and sophisticated quantitative research as the primary quality measurement of hospitality journals (Crawford-Welch \& McCleary, 1992). 
There has been some criticism of publication counting methods being used to report research productivity. Some researchers contend that counting methods are too subjective in terms of journal selection, timeframes, and sampling procedures (Losekoot, Verginis \& Wood, 2001). However, the publication counting method has been frequently used to measure research quality and quantity (Wood, 1995). The publication counting method remains a standard practice within academic institutions as many times the counting of articles is done to add objectivity to the documents disclosing requirements for tenure and promotion of faculty. Though healthful and professionally cynical debate surrounding the best methods for assessing research output of institutions continue, many studies employ publication counting or frequency methods to measure the quantity of contributions. Finally, to overcome a portion of the quality argument, these journals are all blind reviewed securing the fact that the work meets the minimum criteria of each representative editorial review board associated with each particular journal.

Researchers using the counting method to report publication frequencies may ameliorate limitations by expanding the number of selected journals and by providing data on varied timeframes. For this reason, the authors chose to review 11 journals over a period of five recent years, which updates and extends the recently published article by Jogaratnam et al. (2005) in the Journal of Hospitality and Tourism Research. This update also allows for the selection of the top 100 programs according to instances in these journals. Though many general hospitality and tourism reviews have been published, none have included recent activities that provide current information concerning the 11 journals noted in this study.

\section{METHOD}


A counting or frequency method was employed to develop a recent five-year snapshot and to provide data that is comparable with the previously mentioned article (Jogaratnam et al., 2005). Researchers utilized a database manager with Microsoft Office Excel. They counted and recorded all of the necessary information into a database. One researcher coded or entered the articles by journal into the database and another researcher verified the accuracy of the process by re-entering the data. Once the data was entered, the researchers started the counting process for instances, authors and institutions. Two researchers were in charge of a database. When the tables were constructed these researchers compared data from their respective databases. When inconsistencies existed, the researchers recounted the area for inconsistencies (i.e., recounting where inconsistencies were uncovered) until the database was deemed accurate. The third reviewer provided oversight to the steps of the two researchers who were constructing the database as a further check for accuracy in logic and reason.

The reviewed journals are refereed and have over 10 volumes of publishing history. The general hospitality journals included: CHRAQ, FIUHR, JHLM, and JHTR. The travel and tourism journals included: Annals, JTR, and TM. A final group of journals was added to enhance breadth and international viewpoints also replicating the logic of the previous study (Jogaratnam et al., 2005). These journals included: the IJCHM, IJHM, JHTE, and the JTTM. As mentioned earlier, an inclusive list of journals examined here is listed in Table 1.

The selected journals employ a double-blind peer review process for manuscript selection providing an assumption that the published articles possess appropriate quality levels (Jogaratnam et al., 2005; Rutherford \& Samenfink, 2002b). It was not the intent of the researchers to analyze the quality but rather the quantity of articles published. A count was conducted using a procedure that provides actual numbers of instances (i.e., instances of articles, 
and instances of authors). This method is unlike other methods that use the number of citations or total volume and has been used and justified by other authors (e.g., Barry, 1990; Jogaratnam et al., 2005; Sheldon, 1991). The researchers analyzed total output of institutions and authors through counting the instances of articles and authors represented across the analysis period and across the journals analyzed.

"Instances" refers to the number of times a university or author is represented in a journal. The study analysis used "university instances," “article instances,” and "author instances," as the primary units of analysis in this study. For example, if an article were cowritten by an author from Virginia Polytechnic Institute and State University and an author from Purdue University that would be counted as one "university instance" for each Virginia Polytechnic Institute and State University and one “university instance” for Purdue University. Also, credit for an article is not adjusted based on multiple authored papers; though some have called for fractional awarding of credit by multiple authors, no partial credit was calculated in this analysis, keeping with past output reviews (e.g., Barry, 1990). As a quality check and also another metric, the number of articles counted to provide readers with a comparison between the number of articles and instances.

\section{RESULTS}

A World Ranking of the Top 100 Programs by Research Instances (2002-2006) The top 100 universities that provided the most instances by journal article are presented in Table 2. It also presents the total number of contributing author instances and the total number of articles from an institution. In the case of a tie in instances of articles, the total instances of authors were used. In the case of a tie between article instances and instances of authors, the number of articles was used. No same rank was given to institutions unless they had equal 
instances, authors, and articles. This was simply done in an effort to reduce confusion and to provide a unique number ranking for as many institutions as possible.

\section{Table 2 about here}

Data presented includes the top 100 institutions by research output, ranked according to total instances across 11 journals over a recent five-year period. The total number of authors and article instances is presented. The most recent top five contributors by instances along with the associated absolute number of instances from the year 2002 through the year 2006 were: 1) Hong Kong Polytechnic University (211 instances), 2) Cornell University (128 instances), 3) University of Nevada at Las Vegas (104 instances), 4) Pennsylvania State University (99 instances), and 5) University of Surrey (79 instances).

The past 10-year review presented by Jogaratnam et al. (2005), showed the following rankings: 1) Cornell University (354 instances), 2) Michigan State University (248 instances), 3) Virginia Polytechnic Institute and State University (194 instances), 4) Hong Kong Polytechnic University (185 instances), and 5) University of Nevada at Las Vegas (174 instances). Hong Kong Polytechnic University repositioned to first from a previous fourth place. The University of Surrey became the institution with the fifth most volume in the 11 journals while Virginia Polytechnic Institute and State University moved to sixth place. Pennsylvania State University is fourth in the ranking and Michigan State University was second in the prior study and is now ninth.

The top five institutions by number of author contribution to these 11 journals for the five-year period from the years 2002 through the year 2006 along with their associated absolute 
number of authors include 1) Hong Kong Polytechnic University (68 authors), 2) Cornell University (51 authors), 3) University of Nevada at Las Vegas (47 authors), 4) Pennsylvania State University (36 authors), and 5) University of Surrey (37 authors). This can be compared with the number of contributing authors from 10-year period of 1992 through 2001 in the Jogaratnam et al. (2005) study that revealed 1) Cornell University (106 authors), 2) Pennsylvania State University (73 authors), 3) University of Nevada at Las Vegas (72 authors), 4) Hong Kong Polytechnic University (68 authors), and 5) University of Surrey (48 authors).

When comparing and updating the article from the JHTR Jogaratnam et al. (2005) study, Cornell had many less contributing authors over the recent period of five years than during the previous 10 -year period across these 11 journals. This does not imply less contribution to research by Cornell faculty but fewer contributions to the 11 journals studied. The results further showed that Virginia Polytechnic Institute and State University had more than 40 contributing authors during the 10-year period versus 27 during the recent five-year period. Additionally, the data indicated that Oklahoma State University had 20 contributing authors produce 65 instances during the most recent five-year period analyzed. This was the largest increase noted placing Oklahoma State University as the eighth most productive institution amongst the top 100.

The World Top 20 Programs by Journal Contribution (2002-2006) Additionally, the contributions to the 11 journals for the top 20 institutions were compiled to reveal the contributions of the top 20 by journal title over the five-year period. This data is presented in Table 3. It allows a further detailed look at where various institutions are publishing their research output. 
Table 3 about here

For the five-year period analyzed, and as compared with the other universities reported, Hong Kong Polytechnic University made the most contributions to five of the journals including 1) IJCHM, 2) IJHM, 3) JHTR, 4) JTTM, and 5) TM confirming the large growth in publications for that institution. Cornell University was the largest contributor to the CHRAQ with approximate instances of 68 of the 86 total instances reported amongst the top twenty institutions. For Annals, the University of Surrey and Texas A\&M University were tied as the largest contributors out of the top twenty institutions. For the JHLM, Virginia Polytechnic Institute and State University and Michigan State University were the most frequent contributors while University of Nevada at Las Vegas was the most frequent contributor to the JHTE. Michigan State University was also the most frequent contributor to the FIUHR. Texas A\&M University was the most frequent contributor to the JTR.

The Contributions of the World Regions Classified by Journal (2002-2006)

Of further interest, the absolute and relative contributions of world regions to the 11 journals are listed at the bottom of Table 4. These numbers indicate the relative contribution in absolute numbers and percentages for the research instances analyzed. It is important to keep in mind that where two authors from different regions contributed an article, that each region got an instance. In this regard, Table 4 will be inflated by those journals with the most authors across regions. Since journals are published in various times and according to various rules with some featuring many short research briefs, research in progress, and research in full sections, no conclusions can be drawn about the contributions of the journals from the data presented. 
Table 4 about here

However, the numbers have been presented since they may be of interest to various readers. For example, TM indicates a relatively high number of 406 instances with a total relative contribution of $18.59 \%$ of the total research output. Annals contributed 257 instances and $11.77 \%$ of the total. The third is the IJCHM with 273 or $12.50 \%$ of the contributions followed by the IJHM with 191 instances or $8.75 \%$ of the contributions to instances. The fifth journal is the JTTM with 195 instances making up 8.93\% of the total contributed instances by regions across the 11 journals for the five-year period analyzed.

The contributions to journals by geographic area were tabulated in an effort to observe the most significant contributors by region across the 11 journals analyzed. The totals by region across the 11 journals are given in Table 3, both listed by percentages and absolute totals. Of course, the location of the editor of the journal and the country represented may have some impact on the authors publishing in that journal. As can be seen in Table 4, certain journals based out of North America have a solid number of contributors from North America including, but not limited to, CHRAQ, JHTE and FIUHR. The biggest difference in these findings as compared to the 10-year period analyzed by Jogaratnam et al. (2005) was that Asia has become a substantial contributor across 11 journals going from 6.3\% (see Jogaratnam et al. (2005)) of all contributions in the period analyzed by Jogaratnam et al. (2005) to approximately $15 \%$ of all contributions to these journals over the five-year period analyzed. This indicates that Asia is the continent with the fastest rate of growth in research contribution which is no surprise given the rankings and changes in the earlier tables. 
For all 11 journals, the contributors by region indicated that North America produced the greatest number of instances in journals, totaling 1,027 instances and making up $47.02 \%$ of the contributions. Second is Europe with 520 instances making up 23.81\% of the contributions over the past five-year period. Third is Asia with $14.84 \%$ or 365 instances, followed by Australia with 214 instances representing 9.80\%. The significance of rapid growth in the research output of Asia is likely due to the increase in number of hotel schools in Taiwan and Hong Kong and due to the research commitment made by Hong Kong Polytechnic University. Of equal importance though smaller in numbers are the other geographical areas including but not limited to Africa, the Middle East, Latin America, and South America with $1.60 \%, 1.83 \%, .73 \%$ and $.37 \%$ respectively.

A World Ranking of the Top 18 Programs by Research Output (1992-2006)

Table 5 presents the top 18 institutions over the 15 -year period. Combining the top producing universities from the previously reported data (i.e., the top twenty) and the reported data here (i.e., the top 100) allowed for an aggregated list of the top producers. Since the only data available from the previous study was the top 20 , that is the only data available for the period of 1992 to 2001. This resulted in a listing of the top 18 institutions ranked according to total research volume in the 11 journals over the 15 -year period. For comparative purposes, the data from the recent five-year period and the previously reported data for the 10-year period are reported.

By university instances, the top five contributors to these 11 journals for the 15 -year period of 1992-2006 included 1) Cornell University (480 article instances), 2) Hong Kong Polytechnic University (396 article instances), 3) Michigan State University (307 article 
instances), 4) University of Nevada at Las Vegas (278 article instances), and 5) Pennsylvania State University (261 article instances).

Table 5 about here

\section{DISCUSSION AND CONCLUSIONS}

This article argued that a counting method of refereed journals can provide significant information related to the top research producing universities, and can provide helpful information for purposes of comparison of data across ratings of programs and universities. Next, by employing a counting method a database was created which helped identify the top 100 hospitality and tourism programs by instances. Additional information was also provided related to the number of articles and authors. Also, a previous 1992 to 2001 JHTR article was updated to include the years 2002 to 2006. The top university by instances to the 11 journals across the five-year period was Hong Kong Polytechnic University up from fourth in the comparison study to the same 11 journals over a 10-year period. Next, a 15-year total for contributions made to 11 journals was created with the available data from the Jogaratnam et al. (2005) article and from the data from the current database yielding the top 18 programs over a 15-year period of 19922006.

The 15-year tabulation showed many universities that had not previously been in the top 20 analyzed by Jogaratnam et al. (2005) to have now made the list of top producers particularly Oklahoma State University which placed in the top 8 out of the top 100. Additionally, the institutional contributions by journal were totaled to show the contributions made by region by 
the top twenty universities across the 11 journals. The most significant change was the increase in contributions by Asia particularly from Hong Kong like attributable to the large number of contributions of the Hong Kong Polytechnic University and the Chinese University of Hong Kong. North America still had the highest number of accepted manuscripts making up 47.02\% of the total followed by Europe with 23.81\% and then Asia with 14.84\%.

However, most of this article confirmed trends established in the similar study by Jogaratnam et al. (2005). This was particularly true in the larger more established research institutions (e.g., University of Nevada at Las Vegas, Pennsylvania State University) changing little in performance over the periods observed. Certain exceptions were discovered in the number of instances per established institution such as Cornell University and Virginia Polytechnic Institute and State University, possibly subject to changes, as the composition of tenured and tenure-earning faculty becomes altered within institutions or because faculty contribute to other journals outside of the eleven included in this study. Additionally, universities that grow significantly in size and universities with new doctorate of philosophy programs seem likely to increase the number of publications at a quicker rate than other universities. For example, Oklahoma State University’s rank of eighth in the current five-year period after not making the top twenty in the previous 10-year period may be indicative of the establishment of a growing Ph.D program.

While this article does not attempt to assess overall rankings or quality issues among institutions, the information indicates output trends across the 11 journals by the most frequently contributing institutions allowing for the creation of the top one hundred list of contributing universities to hospitality and tourism research. The measurements presented in this study can be used for many reasons including but not limited to 1) assisting hospitality educators in 
identifying research contributions across certain journals, 2) assisting would-be doctoral students with research information by program, and 3) showing changes in contribution at various institutions (e.g., an increasing, decreasing, or stable productivity) over a number of year.

Future studies might produce content analyses to include qualitative and quantitative reports on varying aspects of hospitality and tourism research contributions. Additionally, tables could be included that adjust for single-author versus multiple-author contributions, which is a limitation of this current study as compared to the Jogaratnam et al. (2005) study which featured three levels of frequency of contributions by authors. Additionally, as research databases become more sophisticated, it is more possible for studies to offer information broader in scope than a few journals. For example, some highly specialized institutions may contribute a great deal but to only a select few journals. A more comprehensive database may reveal this information and allow for more comprehensive valuations related to contribution by quality and quantity to be made across programs. Other topics of future interest would be to analyze institutional contributions by subject matter (i.e., tourism, human resource, finance, guest services, marketing etc.), methods employed (i.e., qualitative or quantitative techniques), and to identify the expertise of scholars at different universities in a more useable format that would be helpful for the identification of scholars based on specialty area (i.e., most frequent contributing tourism scholar). This would also prove useful for potential graduate students desiring to select schools based on a focused area of research concentration. Finally, a tiered system of journals combined with a sole versus multiple author reduction may again provide more realistic examples of the work being carried out by various institutions.

The tables by region raise some interesting research questions that merit further investigation as well (Jogaratnam et al., 2005; Ryan, 2005). Are the regions that contribute very 
little to the research also under researched? If this is the case, scholars may attempt to focus international research efforts towards investigations in the geographic regions that have contributed less to the research efforts. Though many of these may not be surprising as they are lesser developed countries, the output can still provide helpful information in determining where research efforts are needed. This may serve those regions well if it could be surmised that those not contributing are under researched and so may need various research output more than other regions that are thoroughly studied.

Regardless of the varying arguments surrounding methodologies, the continued practice of analyzing hospitality and tourism research production provides insights concerning current trends in research. The existing patterns of program expansion and globalization make this an interesting time period to produce studies to track the dissemination of scholarly publications. The fields of hospitality and tourism combine to form a relatively young discipline in comparison to more established academic areas. The proliferation of additional journal titles lends evidence to the assertion that the field is constantly expanding. Future content analyses will provide more insightful snapshots of recognizing development patterns in the hospitality and tourism knowledge base and can help further development the knowledge base in the hospitality and tourism field (Jamal et al., 2007). 


\section{References}

Arpan, L.M., Raney, A.A. \& Zivnuska, S. (2003). A cognitive approach to understanding university image. Corporate Communications, 8(2), 97-113.

Baloglu, S. \& Assante, L. (1999). A content analysis of subject areas and research methods used in five hospitality management journals. Journal of Hospitality and Tourism Research, 23(1), 53-70.

Barry, T.E. (1990). Publication productivity in the three leading U.S. advertising journals: inaugural issues through 1988. Journal of Advertising, 19(Spring), 52-60.

Bolton, M.J. \& Stolcis, G.B. (2003). Ties that do not bind: Musings on the specious relevance of academic research. Public Administration Review, 63(5), 626-630.

Bowen, J. (2005). Managing a research career. International Journal of Contemporary Hospitality Management, 17(6/7), 633-637.

Cheng, L.T., Chan, K.C. \& Chan, R.K. (2003). Publications in major marketing journals: An analysis of research productivity of Asia-Pacific universities. Journal of Marketing Education, 25(2), 163-169.

Chon, K., (2007). Graduate Student Hospitality and Tourism Research Conference. January 4-6, Houston, Texas.

Chon, K., Evans, M., \& Sutherlin, D. (1989). Trends in hospitality management literature: A content analysis. Hospitality Education and Research Journal, 13(3), 483-491.

Clark, G.L. (1985). Productivity ratings of institution based on publication in eight marketing journals: 1983-1984. Journal of Marketing Education, 7(2), 12-23.

Crawford-Welch, S. \& McCleary, K (1992). An identification of the subject areas and research techniques used in five hospitality-related journals. International Journal of Hospitality Management, 11(2), 155-167.

Dann, G, Nash, D. \& Pearce, P. (1988). Methodology in tourism research. Annals of Tourism Research, 15(1), 1-28.

Ferreira, R.R., DeFranco, A.L. \& Rappole, C.L. (1994). Rating hospitality journals. International Journal of Hospitality Management, 13(3), 209-218.

Hing, N., \& Dimmock, K. (1997). Contemporary tourism issues in Asia Pacific Journals 19891996: A thematic perspective. International Journal of Contemporary Hospitality Management, 9(7), 254-269. 
Howey, R., Savage, K, Vergeeten, M, \& Van Hoof, H. (1999). Tourism and hospitality research journals: cross-citations among research communities. Tourism Management, 20(1), 133-139.

Jamal, T., Smith, B., \& Watson, E. (2007). Ranking, rating and scoring of tourism journals: Interdisciplinary challenges and innovations. Tourism Management, 29(1), 66-78.

Jogaratnam, G., Chon, K., McCleary, K., Mena, M. and Yoo, J. (2005). An analysis of institutional contributors to three major academic tourism journals: 1992-2001,” Tourism Management, 26(5), 641-648.

Jogaratnam, G., McCleary, K., Mena, M., \& Yoo, J. (2005). An analysis of hospitality and tourism research institutional contributions, Journal of Hospitality and Tourism Research, 29(3), 356-371.

Losekoot, E., Verginis, C.S. \& Wood, R.C. (2001). Out for the count: Some methodological questions in 'publications counting' literature. International Journal of Hospitality Management, 20(3), 233-244.

McCleary, K.W. \& Weaver, P.A. (1987). A study of publishing activity of the Southern Marketing Association, American Marketing Association, and Academy of Marketing Science for 1986. Proceeding of the Southern Marketing Association Annual Meeting, New Orleans, LA (November).

Neary, J., Mirrlees, J, \& Tirole, J. (2003). Evaluation economics research in Europe: An Introduction. Journal of the European Economic Association, 1(6), 1239-1249.

Newman, D.R., Escoffier, M.R. \& Kay, C. (2001). What do managers read? A survey of journals and periodicals used by lodging managers in the hospitality industry. Journal of Hospitality and Tourism Education, 13(3/4), 76-87.

Pechlaner, H., Zehrer, A., Matzler, K. \& Abfalter, D. (2004). A ranking of international tourism and hospitality journals. Journal of Travel Research, 42(4), 328-332.

Reid, L.J., \& Andereck, K.L. (1989). Statistical analyses use in research. Journal of Travel Research, 28(2), 21-26.

Roberts, C. \& Shea, L. (2005). Editorial: Ranking hospitality and tourism journals. Journal of Hospitality \& Tourism Education, 17(4), 4-4.

Ryan, C. (2005). The ranking and rating of academics in tourism journals. Tourism Management, 26(6), 657-662.

Rutherford, D.G. \& Samenfink, W.H. (1992). Most frequent contributors to the hospitality literature. Hospitality Research Journal, 16(1), 23-29. 
Rutherford, D.G. \& Samenfink, W.H. (2002a). Most frequent contributors to the hospitality literature: A ten-year update. Journal of Hospitality and Tourism Education, 14(3), 515.

Rutherford, D.G. \& Samenfink, W.H. (2002b). Out for the count: a response. International Journal of Hospitality Management, 21(2), 111-117.

Schmidgall, R.S. \& Woods, R.H. (1993). Rating of publishing channels by hospitality faculty. Hospitality Research Journal, 16(3), 89-94.

Schmidgall, R.S. \& Woods, R.H. (1994). CHRIE member perceptions of tenure requirements in hospitality education programs. Hospitality Research Journal, 18(1), 101-120.

Schmidgall, R.S. \& Woods, R.H. (1996). Journal and periodical usefulness as rated by hospitality faculty members. Cornell Hotel and Restaurant Administration Quarterly, 37(2), 47-55.

Sheldon, P.J. \& Collison, F.M. (1990). Faculty review criteria in tourism and hospitality. Annals of Tourism Research, 17(4), 556-567.

Sheldon, P.J. (1991). An authorship analysis of tourism research. Annals of Tourism Research, 18(3), 473-484.

Sturman, M.C. (2005). From the Editor: Reflecting on our recent articles. Cornell Hotel and Restaurant Administration Quarterly, 46(2), 108-109.

Treischmann, J.S., Dennis, A.R., Northcraft, G.B. \& Niemi, A.W. (2000). Serving multiple constituencies in business schools: MBA programs versus research performance. Academy of Management Journal, 43, 1130-1141.

Weaver, P.A. and McCleary, K.W. (1989). Academic contributors: An analysis of academic contributors to four major hospitality journals. Ohio Hospitality Journal, 2(May), 6-11.

Weaver, P.A., McCleary, K.W. and Farrar, A. (1990). Academic contribution to four major hospitality journals revisited. Hospitality and Tourism Educator, 2(3), 30-32.

Weaver, P., Wilson, J.H. \& McCleary, K.W. (1990). Publishing activity of members of three major marketing associations: an update and extension. Journal of Midwest Marketing, 5(Spring), 146-156.

Wood, R.C. (1995). Assessing publications output as an indicator of academic productivity: The case of hospitality management. Tourism Management, 16(3), 171-174.

Woods, R.H. \& Schmidgall, R.S. (1995). Hospitalities influential authors: Using citation analysis to evaluate the research contributions of hospitality faculty and programs. Hospitality and Tourism Educator, 7(1), 66-72. 
Woods, R.H. and Schmidgall, R.S. (2001). Update of hospitality management education's most influential scholars: a citation analysis 1989-1999. Hospitality and Tourism Educator, 13(2), 4-11.

Xiao, H. \& Smith, S.L.J. (2006). The making of tourism research: Insights from a social sciences journal. Annals of Tourism Research, 33(2), 490-507. 
Table 1. Hospitality and Tourism Journals Used in the Analysis

\begin{tabular}{cll}
\hline Abbreviation & \multicolumn{1}{c}{ Journal Name } & \multicolumn{1}{c}{ Editor \& Affiliation } \\
\hline Annals & Annals of Tourism Research & Jafar Jafari, University of Wisconsin, Stout \\
CHRAQ & Cornell Hotel and Restaurant Administration Quarterly & Linda Canina, Cornell University \\
FIUHR & Florida International University Hospitality Review & Marcel Escoffier, Florida International University \\
IJHM & International Journal of Hospitality Management & Abraham Pizam, University of Central Florida \\
IJCHM & International Journal of Contemporary Hospitality Management & Richard Teare, Global University for Lifeline Learning \\
JHLM & Journal of Hospitality and Leisure Marketing & Bonnie Knutson, Michigan State University \\
JHTE & Journal of Hospitality and Tourism Education & Linda O'Shea, University of Massachusetts, Amherst \\
JHTR & Journal of Hospitality and Tourism Research & Kaye Chon, Hong Kong Polytechnic University \\
& Journal of Travel Research & Richard Perdue, Virginia Polytechnic Institute \& State \\
JTR & & University \\
JTTM & Journal of Travel and Tourism Marketing & Kaye Chon, Hong Kong Polytechnic University \\
TM & Tourism Management & Chris Ryan, University of Waikato \\
\hline Notes: The editors represented here were the editors during the period 2002 to 2006. Since then, there have been several changes in editors and /or titles of some of the journals.
\end{tabular}


Table 2. A World Ranking of the Top 100 Programs by Research Instances (2002-2006)

\begin{tabular}{|c|c|c|c|c|}
\hline Rank & Institution & Instances $^{1}$ & Authors $^{2}$ & Articles \\
\hline 1 & Hong Kong Polytechnic University & 211 & 68 & 134 \\
\hline 2 & Cornell University & 128 & 51 & 87 \\
\hline 3 & University of Nevada Las Vegas & 104 & 47 & 69 \\
\hline 4 & Pennsylvania State University & 99 & 36 & 70 \\
\hline 5 & University of Surrey & 79 & 37 & 48 \\
\hline 6 & Virginia Polytechnic Institute and State University & 72 & 27 & 54 \\
\hline 7 & Purdue University & 71 & 27 & 49 \\
\hline 8 & Oklahoma State University & 65 & 20 & 43 \\
\hline 9 & Michigan State University & 59 & 20 & 39 \\
\hline 10 & University of Central Florida & 55 & 18 & 35 \\
\hline 11 & Washington State University & 48 & 12 & 34 \\
\hline 12 & Texas A\&M University & 46 & 15 & 41 \\
\hline 13 & Griffith University & 45 & 31 & 29 \\
\hline 14 & Kansas State University & 37 & 13 & 24 \\
\hline 15 & Iowa State University & 36 & 13 & 24 \\
\hline 16 & University of Houston & 34 & 22 & 12 \\
\hline 17 & Sejong University & 34 & 13 & 30 \\
\hline 18 & University of Illinois at Urbana - Champaign & 33 & 18 & 22 \\
\hline 19 & Eastern Mediterranean University & 30 & 16 & 16 \\
\hline 20 & Chinese University of Hong Kong & 29 & 18 & 16 \\
\hline 21 & University of Guelph & 28 & 17 & 23 \\
\hline 22 & Northern Arizona University & 28 & 14 & 19 \\
\hline 23 & Manchester Metropolitan University & 27 & 10 & 22 \\
\hline 24 & Temple University & 27 & 8 & 20 \\
\hline 25 & Florida International University & 26 & 15 & 20 \\
\hline 26 & University of Queensland & 25 & 17 & 17 \\
\hline 27 & Victoria University & 24 & 15 & 15 \\
\hline 28 & Arizona State University & 24 & 13 & 19 \\
\hline 29 & Ben-Gurion University of the Negev & 24 & 9 & 16 \\
\hline 30 & University of Massachusetts - Amherst & 23 & 13 & 15 \\
\hline 31 & Ohio State University & 22 & 11 & 15 \\
\hline 32 & Sheffield Hallam University & 21 & 15 & 18 \\
\hline 33 & Florida State University & 21 & 13 & 14 \\
\hline 34 & Monash University & 21 & 11 & 16 \\
\hline 35 & University of Nottingham & 20 & 11 & 10 \\
\hline 36 & University of Waikato & 20 & 10 & 16 \\
\hline 37 & Universidad of Las Palmas de Gran Canaria & 20 & 9 & 10 \\
\hline 38 & University of Otago & 19 & 12 & 14 \\
\hline 39 & James Cook University & 19 & 12 & 12 \\
\hline 40 & University of the West Indies & 19 & 10 & 14 \\
\hline 41 & University of Western Australia & 19 & 7 & 9 \\
\hline 42 & Texas Tech University & 18 & 14 & 10 \\
\hline 43 & Universidad de les Illes Balears & 18 & 14 & 8 \\
\hline 44 & University of Strathclyde & 18 & 11 & 15 \\
\hline 45 & Chinese Culture University & 18 & 10 & 11 \\
\hline
\end{tabular}




\begin{tabular}{|c|c|c|c|c|}
\hline Rank & Institution & Instances $^{1}$ & Authors $^{2}$ & Articles $^{3}$ \\
\hline 46 & University of Delaware & 18 & 7 & 14 \\
\hline 47 & Eastern Michigan University & 18 & 7 & 13 \\
\hline 48 & University of Florida & 17 & 9 & 11 \\
\hline 49 & Oxford Brookes University & 17 & 7 & 18 \\
\hline 50 & University of Calgary & 17 & 7 & 14 \\
\hline 51 & Glasgow Caledonian University & 16 & 13 & 10 \\
\hline 52 & University of Alicante & 16 & 10 & 10 \\
\hline 53 & Colorado State University & 16 & 9 & 14 \\
\hline 54 & College of Charleston & 16 & 5 & 10 \\
\hline 55 & University of Missouri - Columbia & 15 & 8 & 7 \\
\hline 56 & Seattle University & 15 & 6 & 6 \\
\hline 57 & Kyunghee University & 15 & 6 & 5 \\
\hline 58 & La Trobe University & 14 & 11 & 10 \\
\hline 58 & University of Brighton & 14 & 11 & 10 \\
\hline 60 & Ming Chuan University & 14 & 11 & 8 \\
\hline 61 & University of North Texas & 14 & 9 & 9 \\
\hline 62 & Lincoln University & 14 & 8 & 8 \\
\hline 62 & University of Valencia & 14 & 8 & 8 \\
\hline 64 & George Washington University & 14 & 4 & 5 \\
\hline 65 & Eindhoven University of Technology & 14 & 4 & 3 \\
\hline 66 & Bournemouth University & 13 & 9 & 11 \\
\hline 67 & East Carolina University & 13 & 6 & 9 \\
\hline 68 & Hebrew University of Jerusalem & 13 & 6 & 8 \\
\hline 69 & Mugla University & 13 & 5 & 9 \\
\hline 70 & Clemson University & 13 & 5 & 7 \\
\hline 71 & University of Stirling & 13 & 4 & 11 \\
\hline 72 & Queen Margaret University College & 12 & 8 & 10 \\
\hline 73 & University of New South Wales & 12 & 7 & 9 \\
\hline 74 & University of Memphis & 12 & 6 & 12 \\
\hline 75 & University of New Orleans & 12 & 6 & 10 \\
\hline 76 & University of Hawaii & 11 & 7 & 9 \\
\hline 77 & RMIT University & 11 & 7 & 7 \\
\hline 78 & Southern Cross University & 11 & 7 & 6 \\
\hline 79 & University of Kentucky & 11 & 5 & 9 \\
\hline 80 & New Mexico State University & 11 & 5 & 5 \\
\hline 81 & Adnan Menderes University & 11 & 4 & 9 \\
\hline 82 & University of Waterloo & 11 & 4 & 8 \\
\hline 83 & Ecole Hoteliere de Lausanne & 9 & 8 & 5 \\
\hline 84 & University of Hawaii at Manoa & 9 & 7 & 4 \\
\hline 85 & San Francisco State University & 9 & 6 & 7 \\
\hline 86 & University of Hong Kong & 9 & 6 & 4 \\
\hline 87 & Leeds Metropolitan University & 9 & 5 & 7 \\
\hline 88 & Massey University & 9 & 5 & 6 \\
\hline 89 & Bowling Green State University & 9 & 5 & 3 \\
\hline 90 & Kaohsiung Hospitality College & 8 & 5 & 8 \\
\hline 91 & San Deigo State University & 8 & 5 & 6 \\
\hline 92 & Yonsei University & 8 & 3 & 7 \\
\hline
\end{tabular}




\begin{tabular}{|c|c|c|c|c|}
\hline Rank & Institution & Instances $^{1}$ & Authors $^{2}$ & Articles $^{3}$ \\
\hline 93 & East Tennessee State University & 8 & 2 & 6 \\
\hline 94 & Georgia Southern University & 7 & 6 & 5 \\
\hline 95 & Ryerson University & 7 & 5 & 6 \\
\hline 96 & Brock University & 7 & 5 & 4 \\
\hline 96 & University of Southern Mississippi & 7 & 5 & 4 \\
\hline 98 & University of Utah & 7 & 4 & 7 \\
\hline 99 & University of Western Sydney & 7 & 4 & 6 \\
\hline 100 & University of Wollongong & 7 & 4 & 5 \\
\hline
\end{tabular}

Notes to Table: ${ }^{1}$ Rank refers to the absolute number of research instances. In the case of a tie in instances, number of authors was considered to break the tie. In the case of ties based on instances and number of authors, the number of articles was used to break the tie. This resulted in only one tie for 96 .

${ }^{2}$ Instances refer to the total count of journal articles for the University - if two authors are listed from one university, then two instances are awarded thus this ranking is inflated based on dual authorship. The number of contributing authors and the number of articles are presented to give a better indication of the output as well.

${ }^{3}$ One article occurrence is equal to the number of articles from the university. This number was not double counted for dual authorship at the same university but if the same article was co-authored by an individual at Georgia Southern University and University of Western Sydney, then each institution would receive one occurrence for an article. Thus, this score is slightly inflated for dual authorship between universities. These biases are likely not big enough to change rank at the top of the table but of course become more sizeable due to smaller absolute numbers. 
Table 3. The World Top 20 Programs Classified by Journal Contribution (2002-2006)

\begin{tabular}{|c|c|c|c|c|c|c|c|c|c|c|c|c|c|}
\hline No. & Institution & Annals & CHRAQ & FIUHR & IJCHM & IJHM & JHLM & JHTE & JHTR & JTR & JTTM & $\mathrm{TM}$ & Total \\
\hline 1 & Hong Kong Polytechnic University & 6 & 2 & 5 & 18 & 26 & 2 & 5 & 20 & 9 & 19 & 20 & 132 \\
\hline 2 & Cornell University & $*$ & 68 & 3 & 1 & 4 & 1 & 1 & 7 & 1 & $*$ & $*$ & 86 \\
\hline 3 & University of Nevada at Las Vegas & $*$ & 6 & 5 & 9 & 8 & 1 & 11 & 16 & 1 & 9 & 4 & 70 \\
\hline 4 & Pennsylvania State University & 4 & 10 & 3 & 5 & 6 & 8 & 4 & 16 & 5 & 3 & 5 & 69 \\
\hline 5 & University of Surrey & 7 & 2 & 2 & 5 & 6 & 5 & * & 2 & 9 & 3 & 7 & 48 \\
\hline 6 & Virginia Polytechnic \& State University & 6 & * & 1 & 3 & 5 & 9 & 4 & 11 & 3 & 5 & 5 & 52 \\
\hline 7 & Purdue University & 2 & 2 & 1 & 2 & 1 & 6 & 8 & 4 & 2 & 12 & 9 & 49 \\
\hline 8 & Oklahoma State University & 1 & 2 & 3 & 1 & 8 & 4 & 5 & 6 & 1 & 8 & 4 & 43 \\
\hline 9 & Michigan State University & 2 & 4 & 11 & 3 & $*$ & 9 & 2 & $*$ & 6 & 2 & $*$ & 39 \\
\hline 10 & University of Central Florida & $*$ & 2 & 3 & 2 & 8 & 6 & 1 & 2 & 2 & 4 & 4 & 34 \\
\hline 11 & Washington State University & 6 & $*$ & 2 & $*$ & 8 & 2 & 5 & 6 & $*$ & 1 & 4 & 34 \\
\hline 12 & Texas A\&M University & 7 & * & $*$ & * & 1 & $*$ & 1 & 1 & 11 & 3 & 16 & 40 \\
\hline 13 & Griffith University & 3 & 1 & $*$ & 5 & 4 & 1 & $*$ & 2 & 1 & 1 & 11 & 29 \\
\hline 14 & Kansas State University & 2 & $*$ & $*$ & 1 & 2 & 2 & 4 & 6 & 2 & 5 & 3 & 27 \\
\hline 15 & Iowa State University & 1 & 1 & * & 2 & 4 & 4 & 4 & 4 & 1 & 1 & 1 & 23 \\
\hline 16 & University of Houston & $*$ & 2 & 1 & 7 & $*$ & $*$ & 3 & $*$ & * & 3 & $*$ & 16 \\
\hline 17 & Sejong University & 3 & 1 & * & 1 & $*$ & 1 & $*$ & 2 & 2 & $*$ & 18 & 28 \\
\hline 18 & University of Illinois, Urbana Champagne & 3 & 3 & $*$ & $*$ & 1 & $*$ & 1 & 1 & 3 & 2 & 7 & 21 \\
\hline 19 & Eastern Mediterranean University & $*$ & $*$ & $*$ & 7 & 1 & 1 & $*$ & $*$ & $*$ & 1 & 5 & 15 \\
\hline \multirow[t]{2}{*}{20} & Chinese University of Hong Kong & $*$ & 4 & $*$ & 1 & 8 & $*$ & $*$ & 3 & $*$ & $*$ & $*$ & 16 \\
\hline & Total & 53 & 110 & 40 & 73 & 101 & 62 & 59 & 109 & 59 & 82 & 123 & 871 \\
\hline
\end{tabular}


Table 4. The Contributions of the World Regions Classified by Journal (2002-2006)

\begin{tabular}{|c|c|c|c|c|c|c|c|c|c|c|c|c|c|c|c|c|c|c|c|c|c|c|c|c|}
\hline Journal & \multirow{2}{*}{\multicolumn{2}{|c|}{ Annals }} & \multirow{2}{*}{\multicolumn{2}{|c|}{ CHRAQ }} & \multirow{2}{*}{\multicolumn{2}{|c|}{ FIUHR }} & \multirow{2}{*}{\multicolumn{2}{|c|}{ IJCHM }} & \multirow{2}{*}{\multicolumn{2}{|c|}{ IJHM }} & \multirow{2}{*}{\multicolumn{2}{|c|}{ JHLM }} & \multirow{2}{*}{\multicolumn{2}{|c|}{ JHTE }} & \multirow{2}{*}{\multicolumn{2}{|c|}{ JHTR }} & \multirow{2}{*}{\multicolumn{2}{|c|}{ JTR }} & \multirow{2}{*}{\multicolumn{2}{|c|}{ JTTM }} & \multirow{2}{*}{\multicolumn{2}{|c|}{$\mathrm{TM}$}} & \multicolumn{2}{|c|}{ Total $^{2}$} \\
\hline Region & & & & & & & & & & & & & & & & & & & & & & & No. & Percent \\
\hline Africa & \multicolumn{2}{|c|}{$2^{1}$} & \multicolumn{2}{|c|}{-} & \multicolumn{2}{|c|}{-} & \multicolumn{2}{|c|}{3} & \multicolumn{2}{|c|}{1} & \multicolumn{2}{|c|}{-} & \multicolumn{2}{|c|}{-} & \multicolumn{2}{|c|}{-} & \multicolumn{2}{|c|}{1} & \multicolumn{2}{|c|}{2} & \multicolumn{2}{|c|}{7} & 35 & 1.60 \\
\hline Asia & \multicolumn{2}{|c|}{19} & \multicolumn{2}{|c|}{14} & \multicolumn{2}{|c|}{6} & \multicolumn{2}{|c|}{28} & \multicolumn{2}{|c|}{40} & \multicolumn{2}{|c|}{12} & \multicolumn{2}{|c|}{8} & & & & & & & & & 324 & 14.84 \\
\hline Australia & & 0 & & & & & & & & & & & & & & & & & & & & 3 & 214 & 9.80 \\
\hline Europe & & 6 & & & & & & 0 & & & & & & & & & & & & & & 2 & 520 & 23.81 \\
\hline $\begin{array}{c}\text { Latin } \\
\text { America }\end{array}$ & & 2 & & & & & & & & & & & & & & & & & & & & & 16 & .73 \\
\hline Mid East & & 7 & & & & & & ; & & & & & & & & & & & & & & & 40 & 1.83 \\
\hline $\begin{array}{c}\text { North } \\
\text { America }\end{array}$ & & 0 & & & & & & & & & & & & & & & & & & & & & 1027 & 47.02 \\
\hline $\begin{array}{c}\text { South } \\
\text { America }\end{array}$ & & 2 & & & & & & & & & & & & & & & & & & & & & 8 & .37 \\
\hline Journal & & nals & & $\mathrm{AQ}$ & & $\mathrm{HR}$ & & $\mathrm{HM}$ & & & & & & & & & & & & & & & & otal \\
\hline & No. & $\%$ & No. & $\%$ & No. & $\%$ & No. & $\%$ & No. & $\%$ & No. & $\%$ & No. & $\%$ & No. & $\%$ & No. & $\%$ & No. & $\%$ & No. & $\%$ & No. & Percent \\
\hline Total $^{3}$ & 257 & 11.77 & 188 & 8.61 & 76 & 3.48 & 273 & 12.50 & 191 & 8.75 & 140 & 6.41 & 120 & 5.49 & 163 & 7.46 & 175 & 8.01 & 195 & 8.93 & 406 & 18.59 & 2184 & 100 \\
\hline
\end{tabular}

Table Footnotes: ${ }^{1}$ Absolute number of occurrences for regions and journals. Explanation: A simple article count sorted by region. Co-written articles in more than one region such as in Asia and in Latin America are given one occurrence for each region (i.e., the total number of articles will be greater than the total number of articles published in that journal during that period due to this inflation factor). The purpose of the table was to examine at contribution by geographic region to articles. ${ }^{2}$ This column represents the geographic region total for the 11 journals from 2002 to 2006 with Number (No.) representing the absolute number and Percent representing the relative or percentage total article occurrence by region when compared to total contributions by all regions. ${ }^{3}$ This represents the total absolute number (No.) and the relative contribution of instances to the total combined instance contribution for all the journals. For example, Annals contributed 257 instances or $11.77 \%$ of all the works published in this dataset. 
Table 5. A World Ranking of the Top 18 Programs by Research Output (1992-2006)

\begin{tabular}{|c|c|c|c|c|}
\hline Rank $^{1}$ & 1992 to $2006^{2}$ & Institution & 1992 to 2001 & 2002 to 2006 \\
\hline 1 & 480 & Cornell University & 352 & 128 \\
\hline 2 & 396 & Hong Kong Polytechnic University & 185 & 211 \\
\hline 3 & 307 & Michigan State University & 248 & 104 \\
\hline 4 & 278 & University of Nevada Las Vegas & 174 & 99 \\
\hline 5 & 261 & Pennsylvania State University & 162 & 72 \\
\hline 6 & 266 & Virginia Polytechnic \& State University & 194 & 79 \\
\hline 7 & 229 & Purdue University & 158 & 59 \\
\hline 8 & 187 & University of Surrey & 110 & 45 \\
\hline 9 & 165 & University of Central Florida & 72 & 28 \\
\hline 10 & 117 & Griffith University & 85 & 46 \\
\hline 11 & 113 & Northern Arizona University & 69 & 37 \\
\hline 12 & 115 & Texas A\&M University & 65 & 48 \\
\hline 13 & 102 & Kansas State University & 52 & 34 \\
\hline 16 & 100 & Washington State University & 64 & 23 \\
\hline 14 & 98 & University of Houston & 68 & 45 \\
\hline 15 & 91 & University of Massachusetts - Amherst & 47 & 27 \\
\hline 17 & 72 & Manchester Metropolitan University & & 19 \\
\hline 18 & 66 & James Cook University & & 79 \\
\hline
\end{tabular}

Note: ${ }^{1}$ Database used is compiled from the top lists by instances for the 2002-2006 period, and from the data available from the top twenty in the JHTR Jogaratnam et al. (2005) article for 1992 to2001. Data limited to the combining the two top 20 from which a top 18 across the 11 journals analyzed over a period of 15 years was found. These totals were then ranked to arrive at the total. ${ }^{2} \mathrm{~A}$ simple totaling of the 1992 to 2001 column with the 2002 to 2006 allowed for the 1992 to 2006 summations. 
